\title{
Providing economic security for regional businesses
}

\author{
Yuriy Alekseevich Bukhantzev \\ Volgograd State University \\ The Institute of economics and finance \\ Volgograd, Russia \\ bukhantzev@yandex.ru
}

\author{
Anna Sergeevna Khudyakova \\ Volgograd State University \\ The Institute of economics and finance \\ Volgograd, Russia \\ aasshh@yandex.ru
}

\author{
Anna Pavlovna Altukhova \\ Volgograd State University \\ The Institute of economics and finance \\ Volgograd, Russia \\ ap.altuhova@yandex.ru
}

\begin{abstract}
As the local business development level directly shapes the regional economy, the variety of internal and external risks these very enterprises are subject to in their daily activities, truly complicates their identification. Tackling this issue presents a major challenge for selecting specific management instruments like accounting, control and analysis, planning and forecasting. It is the lack of an integrated approach to the process of threat identification and prevention that characterizes the current state of economic security systems in place. This study is aimed to both assess the overall quality of such systems utilized by the local businesses and to elaborate a set of organizational and methodological measures to raise their efficiency. The research also provides an analysis of the utilized conceptual apparatus. The article defines the economic security subsystems as well as the principles and procedures they are based upon as a comprehensive provision for the economic safety of the region on the whole, with contemporary internal control methods as the main tools. The authors have investigated the internal control framework with its close ties with accounting and economic analysis, while distinguishing accounting control functions from control functions as a system. An internal audit service is finally suggested to ensure the economic security of the Volgograd region city-forming businesses.
\end{abstract}

Keywords - economic security of an enterprise, internal control system, economic security threats

\section{INTRODUCTION}

Volgograd region-based businesses face some significant economic threats being brought along by the modern competitive environment trends on a daily basis: diminishing investment attractiveness, excessive dependence on external financing, internal economic miscalculations leading to contract breaches and growth of payables, ineffective commercial lending, administrative barriers, unpredictability of the foreign-trade policies, aggressive competition, raiding, etc. At the same time, just anything from this short list above can cause some serious financial losses. Such circumstances deem it necessary for the local top-management to pay constant and quite close attention to the economic security issues in order to uphold efficiency, stability and independence of their companies.

It becomes particularly important for those large backbone enterprises, that account for more than $60 \%$ of industrial production according to the Volgograd regional Committee for industry and trade: OOO "LUKOILVolgogradneftepererabotka, OOO LUKOIL-KGPZ", JSC "Caustic", CJSC "Nikomag", LLC "VMK "VGTZ", OJV "EPK Volzhskiy", OJSC "Volgogradneftemash", JSC "SUAL" (VGAZ), JSC "Volzhsky pipe plant", JSC "Redaelli SSM" branch "Volgogradskiy", JSC "Plant "Meteor", JSC "Institute of HydroMash "Shtil", LLC "EuroChem-Volgakaliy" and "CDB "Titan" Ltd, JSC "VMK "Red October", JSC "Volzhskiy Orgsintez", JSC "Volga-FEST", ZAO "Pipe works "Profil - Okras im. Makarova", Volgograd branch of "Omsktechuglerod" Ltd, JSC "Voltyre-Prom", JSC "Volzhsky abrasive plant", JSC "Kamyshinsky glass", JSC "Gazprom Khimvolokno", JSC "Kamyshin textiles", LLC "the Firm", LLC "Kamyshinsky textile mill", JSC "EKTOS-Volga", CJSC "Gasprom-Kran" JSC "PK Akhtuba", JSC "Volzhskrezinotechnika", LLC "Kamyshin plant bench assembling instrument", LLC "Kamyshinsky Mashzavod", LLC "Kamyshin drilling tool plant", JSC "Uryupinsk crane plant". Moreover, the current study has already identified these as experiencing significant economic security problems.

While undergoing some massive transformation, the Russian national security system requires its national business structures to follow it in the process as the new economic conditions press on, thus urging to rethink the approaches and capabilities of the key management system elements.

Thus, some theory is called for in order to devise principles and methods of reaching an adequate level of economic security for individual enterprises.

Despite the increased attention of researchers to this problem, it is to be noted that the issues like comprehensive economic security, creation of internal controls and appropriate methods have not yet been worked out well enough. So, as in relation to an individual enterprise the 
concepts of a economic security system and its state are still debatable while no clear systematization of economic threats exists either.

\section{MATERIALS AND METHODS (MODEL)}

A dialectical approach has been applied as a methodological basis while studying the results of Volgograd region economic activity and the processes involved therein.

Common scientific methods like process and system approaches to the studied problems were also utilized in the course of this study.

The first phase is focused on the conceptual apparatus examination and basic economic security system constructing principles.

At the second phase the study has identified and analyzed some specific sources and mechanics of the internal economic security system creation associated with the structural and functional features of the objects studied. Also here we have defined both the management subsystems' cross relations and how the process of achieving the right level of economic security can fundamentally differ from case to case.

We have analyzed and evaluated the existing systems of data support, internal financial control and audit, risk management and all of the elements they were comprised of as well as the level of organizational, managerial and personnel commitment to provide for the internal management.

The performed activity analysis of the regional backbone enterprises is based on allocating and exploring the companies' internal key business processes and interlinks with the outside environment.

We have also determined the sources of qualitative changes in an enterprise management system founded on the characteristics of increasing economic security levels. Thereafter the recommendations for improving internal controls, risk management and internal audit systems have been developed.

In general the underlying theoretical fundament of this research is comprised of domestic and foreign economic security studies concerning engineering and methodology, data and analytical support, internal controls on the whole and in parts consequently.

\section{RESULTS AND DISCUSSION}

In fact the concept of the organizational economic security has not been fixed at the specification level, but various authors do provide all sorts of interpretations.

I. A. Blank believes that an entity's economic security is a state and place of an organization in the matrix of its interrelations enabling the one to survive and progress despite internal and external threats, including the immediate influences of both unpredictable and difficult to forecast factors. [1]

Mr A. A. Odintsov considers an entity's economic security to be a state when a company makes the most effective use of corporate resources available preventing threats and ensuring its stable functioning both at present and in perspective. [2]

Mrs T. E. Kochergina defines an entity's economic security as a both quantitative and qualitative characteristic of the company's properties, reflecting its ability to survive on its own and grow while facing external and internal economic threats. [3]

Mr. V. V. Shlykov describes the economic security of an enterprise as such a state when its vital interests are guarded from both real and potential sources of dangers and threats. [4]

The provided definitions emphasize the inherent characteristics of an economic safety state that determine the specific activities targeted at ensuring it:

- The internal and external threats are in place;

- The countermeasures are preventive by nature;

- A focus on a maximum possible result in the process of achieving the set out goals.

The presence of internal and external threats calls for a need to use both internal and external sources to generate and process data.

The preventive nature of countermeasures fundamentally presses for extracting economic security issues from the existing number of management subsystems including the classic accounting, control and analysis aimed primarily at assessing past and current events. However, the preventive nature of a planning and forecasting system does not imply a 360-degree threat evaluation and elaboration of countermeasures like an economic security system does.

Such fundamental differences do not suggest isolating the process of ensuring economic safety from a corporate system of management. Moreover, the organization's economic security is supported only when all of the subsystems are functioning in unison.

Thus, the characteristics of an economic security equilibrium state let us determine the entity's economic security system as a comprehensive system of forecasting, detection, analysis, prevention and elimination of external and internal threats.

To establish the economic security systems at Volgograd region backbone businesses is to build up the conditions that allow their management to specify and apply methods and approaches for discovering, preventing and consequently effective offsetting threats to the stability of business operations.

The economic security system goals:

- To develop a set of measures and tools for economic security threat identification;

- To analyze the normal course of economic processes and projects;

- To elaborate maintenance measures for the stable functioning of the economic system; 
- To prevent business process failures;

- To prevent violations of legal requirements;

- To monitor the implementation of internal standards and regulations;

- To provide a comprehensive analysis of cross-border economic and contractual relations..

Researching Volgograd region backbone enterprises' real activity has allowed us to postulate the most common threats to their sustainable development:

- unfair competition including illegal actions;

- price imbalance;

- insufficient level of investment resources;

- low organizational solvency rates;

- irrational price regulation;

- rapid changes in legislation, exchange and interest rates;

- illegal disclosure of confidential information;

- fraud and theft of funds;

- management and government corruption.

Overall it is vital to employ a systematic approach to ensure the entity's economic security as it allows for a more efficient use of resources and continuous operation.

We view an economic security system as a multilevel one, with a number of subsystems:

- an accounting subsystem;

- a control subsystem;

- an analytical subsystem;

- a planning and forecasting subsystem.

The economic security problems commonly relate to the limited functionality of these subsystems.

Accounting and data related activities carried out by the accounting subsystem are the important elements of the organizational economic security system. Accounting is a business process aimed at the creation of the documented, systematized data concerning objects, in compliance with legal requirements, and preparation of financial statements based on it [5].

It is the accounting system that provides the information on a business profitability. An organization needs to maintain proper accounting records and adjust its objectives to ensure economic security and sustainable development. Accounting provides reliable and necessary information for management decisions.

However, due to legal requirements the information generated by an accounting system does not really comply with the just-in-time principle vital for developing economic security preventive measures, and represents only the basis for analytical procedures and control.

A control subsystem is not regulated by normative documents, but is rather based on accounting information except when controlling is not formalized. At the same time, when the accounting process is adequately controlled internally, it really contributes to the complete and reliable picture.

Internal control is an economic security system element, which is a protective mechanism ensuring the business owner protection and elimination of shortcomings in the financial and economic activities of the organization. It carries out the most important task of keeping the business functioning, defines legality, expediency, efficiency of business activities.

The main internal control tasks [6]:

- to assess the internal control system adequacy checking the chain of management, providing proposals to address shortcomings and recommendations to raise management efficiency;

- to evaluate the overall performance arranging organizational functional analysis and delivering proposals for improvement.

Internal control contributes to the achievement of business goals. It should detect and prevent any deviations from the established rules and procedures, as well as distortions in accounting, financial, managerial and other reporting.

Accounting and control subsystems have common stages of implementation: preparation of an entity's economic data, its analysis and evaluation, validation of such information and error correction jointly with the control services. A volume of accounting and analytical data is formed as a result of their interaction. Combining accounting and control subsystems, characterizes the current control of the accounting and analytical process level and the economic entity itself. The interaction of accounting and analytical subsystems represents the ongoing control and planning of the subject. A combination of analytical and control subsystems comprises a solid ground for assessing and identifying business risks in the course of daily organizational activities[7].

The functional orientation of the system determines the internal control main stages and procedures, that concentrate not only on the confirmation of compliance with legal accounting requirements but primarily on the verification of compliance with the results of the internal policy, their economic feasibility and validation of information generated at all management levels.

Internal control procedures:

- assessment of analytical indicators;

- development of proposals to optimize processes, their accounting;

- evaluation and development of internal process regulation and accounting; 
- top management consulting, including transactions feasibility analysis;

- assessment of legal aspects of transactions, etc.

Administering internal controls at the Volgograd region backbone enterprises aids to reach a higher quality level for organization's economic security indicators:

- protection and enhancement of assets owned by a business;

- maximize the use of the organization's various resources;

- reliability of financial statements;

- the effectiveness and efficiency of activities;

- compliance with laws and regulations;

- reduction of financial losses;

- fraud and theft prevention;

- protection of confidential information.

A continuous internal control process in any area provides top management with comparable information on the planned and achieved results activities, allowing to identify the causes of differences in results and to adjust them at will.

The analysis of the Volgograd region backbone enterprises activities reveals that at present, many enterprises apply internal control by:

- distributing functions among departments,

- allocating persons responsible for the task performance audit and record keeping;

- creating accountability systems;

- using an Audit Committee to monitor company's financial and economic activities.

All this, undoubtedly gives a certain positive result, but it does not provide appropriate economic security, which puts to question the effectiveness of such measures and emphasizes the urgency of finding new ways to solve this problem.

The analysis of documents, regulating business processes, managerial procedures and operations, internal financial control and internal audit as well as their application, shows an average system indicator of the of economic security development level in the region to reach 2.7 points on a 5point scale. The highest scores were received by:

- financial management procedures - 3.6;

- $\quad$ staff competence - 3.2;

- delineation of roles and responsibilities - 3.2;

- internal financial control procedures - 3.1;

- culture and ethical values - 3.1.

The components receiving an average score:
- development of risks minimizing measures - 2.8;

- control actions and control measures implementation 2.8

- internal audit - 2.8;

- monitoring of controls - 2.5;

- risk identification - 2.4;

The following components have the lowest level of development:

- coordination of internal financial control activities - 2.3 points;

- risk assessment - 2.1 points;

- fixing risk identification, assessment and minimization procedures- 1.8 points;

- labeling risks - 1.5 points.

Such a result proves the economic security systems in general to be rather developed and their subsystems like internal financial control, internal audit and risk management to be consistently utilized.

However, some system elements do not meet the performance criteria.

Certain improvements are required to achieve the needed degree of compliance, including:

- embedding risk management into existing planning and forecasting mechanisms;

- creation of a full-fledged internal control system based on risk management;

- development of relations among structural organizational units concerning risk identification, assessment and minimization;

- coordination of internal control activities;

- ensuring functional independence of internal auditors;

- refocusing the internal audit from detection of violations to the elaboration of recommendations to improve internal control.

Presently the weakening of attention paid to the internal audit services becomes a problem. Thus, according to the results of a recent internal audit services study conducted by the Institute of Internal Auditors, the importance of the internal audit service has fallen from $68 \%$ to $39 \%$. At the same time, just in 2017, $82 \%$ of respondents declared full or significant independence from the executive management. This figure was $83 \%$ in 2013. On the other hand internal auditors still lack the proper authority and powers as well as adequate support from top managers and BODs which is a noted problem.

From our point of view, since the internal auditors are able to carry out a significant amount of control functions assigned to the management of an organization - it is the internal audit 
department that might exercise control over the preparation of objective financial information, evaluating the effectiveness of the internal control system, identifying and managing risks. It is also vital that internal audit departments are embedded in businesses in the vast majority of countries and in fact prove to be effective on a daily basis [8].

Internal audit is vital when a company has geographically dispersed branches or divisions, and the local management makes independent decisions, while top management is in dire need for the reliable information on to monitor and evaluate the decisions taken on the whole.

The following functions should be assigned to the internal audit services of the Volgograd region backbone enterprises:

- verification of accounting and control systems, their monitoring and development of recommendations for improvement;

- verification of accounting and operational information, the study of individual articles of reporting;

- verification of compliance with laws, regulations, accounting policies, management instructions;

- checking the operation of the control units;

- evaluation of the internal control mechanism effectiveness in the structural units;

- verification of assets and liabilities;

- software evaluation;

- special investigations into individual cases, such as suspected authority abuse;

- development of proposals to address shortcomings and improve management efficiency;

- implementation of analytical activities.

The creation of an effective internal audit systems at the Volgograd region backbone enterprises will allow:

- to ensure an effective functioning, sustainability and maximum business progress (according to the set goals) in a highly competitive environment;

- to preserve and effectively use the resources and potential of an organization;

- to timely identify and minimize commercial, financial and other risks in the management of the organization;

- to establish data support systems for all management levels that will be adequate to the constantly changing conditions and that allow entities to duly adapt to changes in internal and external environment.

In practice an efficient internal audit service reduces losses caused by internal factors by $40 \%$ and external by $25 \%$. At the same time, according to the Institute of Internal Auditors, the share of budgets of internal audit services in Russia relative to the annual revenue of companies varies from $0.002 \%$ to $0.63 \%$.

\section{CONCLUSION}

In the end the analysis of Volgograd region backbone enterprises' economic security systems has shown certain problems with forecasting, identification, evaluation and prevention of threats.

The article formulates the roles of accounting, economic analysis and control played in the economic security systems as the integral and interrelated elements of the enterprise management process. The list of control functions is supplemented with the assessment of the internal control system adequacy and performance evaluation.

The main components of economic security systems are analyzed revealing those with the lowest adaptation rate and determining measures for boosting the economic security levels at an enterprise and deterring both internal and external threats.

The internal audit service is designated to be a structure capable of controlling the preparation of objective financial data, evaluating the effectiveness of the internal control system, identifying and managing risks, and coordinating the actions of structural units in this respect.

The authors clarify the internal audit service functions in the economic security system of an enterprise, including: optimization of business partners' selection process, increasing the degree of management responsibility, payment control, day-to-day discipline regulatory review of accounting practices in separate structural units for compliance with the legislation of the Russian Federation and internal regulations, providing analytical data on the economic security level, advising management on optimization of activities.

\section{References}

[1] I. A. Blank / Financial security management in an enterprise. M: Elga, 2009. p.778.

[2] A. A. Odintsov / Economic and information security of a business M.: Academy, 2008. p.336.

[3] T.E. Kochergin / Economic security. Rostov-on-Don:Feniks, 2007. p.448.

[4] V. V. Shlykov / Integrated maintenance of economic safety of a business, Moscow: Aletheia, 1999. p.144.

[5] The federal law "On accounting practices" (as of 06.12.2011 N402-FZ).

[6] Y. A. Bukhantzev., A. V. Glushchenko,. / Accounting, analysis and payment control interaction / The status and development of accounting, economic analysis and audit practices: an interuniversity collection of scientific articles and research papers. - Volgograd: Volgograd scientific publishing house, 2010. - 296 p. (pp. 36-46)].

[7] Y. A. Bukhantzev / Accounting and analytical support for reciprocal payments with contractors // extended abstract of the dissertation for seeking a post-graduate degree in Economic Sciences / Saratov State Socio-Economic University. Volgograd, 2010. - 19 p.].

[8] Y. A. Bukhantzev / Improving internal control efficiency of reciprocal payments with contractors. // Bulletin Of Volgograd State University. Episode 3 " Economics. Ecology " № 1 (14). 2009 - 276 p. (p. 173-178). 